\title{
Time for reflection - time for action
}

n the last half of 2008, the Division of Agriculture and Natural Resources (ANR) began work on a new strategic plan that culminated in the April 2009 Strategic Vision 2025 (http://ucanr.org/About_ANR/Strategic_ Vision). As part of that planning process, panels of experts from within and outside ANR synthesized the most up-to-date research available on expected trends for California. They analyzed California's future structure and considered the systems supporting agriculture and food, natural resources, health and nutrition, and human development.

To summarize, by 2025 California is expected to have 8.5 million more residents, a 22\% increase from 2008 when our strategic planning began, making the state home to an estimated 47 million people. The population will be significantly older, with the proportion of seniors age 60 and older increasing from approximately one in seven to about one in five. The first of the baby-boom generation will reach 65 in 2011, and many projections indicate that, as a whole, California industries will face labor shortages in critical skills. Employment will likely shift from manufacturing and natural resources to service industries, and access to a stable agricultural workforce will continue to be uncertain. Unfortunately, the loss in science literacy in the $\mathrm{K}-12$ population will continue, with expectations that only seven out of every ten students will graduate from high school in 4 years, and only one in four graduates will be ready for college.

Even as an aging population, workforce challenges and eroding science literacy affect California agriculture and its broader economy, the world population will increase by approximately $30 \%$ by 2025 , creating significantly

org/sites/anrstaff/Strategic _ Initiatives). All four of the initiative advisory panels are close to proposing initial areas of inquiry and best opportunities for focused research and education. Initiative leaders aim to focus on areas where significant impacts in limited time frames can be made by leveraging existing research and alternative sources of funding, and building collaborations with new UC and outside

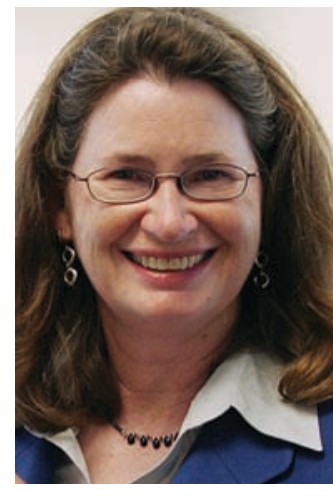

Barbara Allen-Diaz Associate Vice President, Academic Programs and Strategic Initiatives partners.

All four initiatives - sustainable food systems, healthy families and communities, endemic and invasive pests and diseases, and sustainable natural ecosystems - have identified cross-initiative areas such as water, science literacy and youth development, and initiative leaders are working together to incorporate these kinds of crossdisciplinary opportunities into their planning.

At the local level, current projections indicate that our county partners will face even more difficult budget constraints in the coming years. In response, we are examining opportunities to change our traditional county partnerships to ones with expanded boundaries and multicounty partnerships to release administrative resources, save county and UC dollars, and expand program support.

As the Division's current workforce retires, we will focus on allocating resources strategically, building on our breadth of expertise, and securing the essential capacities to discover and deliver new knowledge and policy-relevant science. As I write this, we are hopeful that the final resolution of a state bud-

As I write this, we are hopeful that the final resolution of a state budget - including support for higher education - will allow us to recruit for a significant number of high-priority academic positions. get - including support for higher education will allow us to recruit for a significant number of high-priority academic positions.

This issue of California Agriculture looks at one aspect of importance in human and community development: our aging population. It

greater demand for agricultural products including food, fiber and renewable biofuels. An aging farm population and the continued erosion of scientific expertise in food, and natural resource production, research and education, will challenge food-system sustainability - unless steps are taken to reverse the trend, including educating young people in this area.

Now, 18 months into our implementation of the Strategic Vision, it is an opportune time to reflect on aspects of the information that we have gathered and applied. In order to make the most of ANR's available resources, we have focused our initial attention on four of the nine initiatives outlined in the Vision (http://ucanr. reviews various issues that population change brings to California, and how ANR research and education efforts in these areas can provide information that makes a difference in the lives of California's citizens.

As our population ages, ANR has a tremendous opportunity, and, in fact, a duty to make a difference in educating young people for the future. In addition to the proven success of our 4-H and youth development programs, UC and ANR must focus our brightest minds and best ideas on the state's complex problems, and translate and deliver the best science available to California's entrepreneurs, industry leaders, land managers, policymakers and consumers, both young and old. 